\title{
Effect of Different Pretreatment Solutions on Electrokinetic Remediation of Heavy Metals from Municipal Solid Waste Incineration Fly Ash
}

\author{
Cuijing Han ${ }^{\dagger 1,2}$, Huilin Li $i^{\dagger 1,2}$, Yujie Yan ${ }^{\dagger 1,2}$, Lin Yu ${ }^{\dagger 1,2}$, Huirong Lin $^{\dagger 4}$, Xiao Huang ${ }^{\dagger 1,2}$, \\ Binquan Jiao ${ }^{1,2}$,*, YanChyuan Shiau, ${ }^{3, *}$, Dongwei $\mathrm{Li}^{1,2, *}$ \\ ${ }^{1}$ State Key Laboratory of coal mine disaster dynamics and control, Chongqing University, Chongqing \\ 400044, P.R. China; \\ ${ }^{2}$ School of Resources and Safety Engineering, Chongqing University, Chongqing, 400044, China \\ ${ }^{3}$ Dept. of Construction Management, Chung Hua University, No. 707, Wufu Rd., Sec. 2, Hsinchu \\ 30012, Taiwan. \\ ${ }^{4}$ National and Local Joint Engineering Research Center for Hazardous Waste Integrated Disposal. \\ Chongqing, 401147, China \\ $\uparrow$ These authors contributed equally to the work. \\ *E-mail: j.binquan@cqu.edu.cn (B.Q Jiao); ycshiau@chu.edu.tw (Y.C Shiau); litonwei@cqu.edu.cn \\ (D.W Li)
}

doi: $10.20964 / 2020.09 .31$

Received: 4 May 2020 / Accepted: 12 June 2020 / Published: 10 August 2020

The presence of carbonate and alkaline oxides leads to the strong acid buffering capacity and high $\mathrm{pH}$ of municipal solid waste incineration (MSWI) fly ash, hindering the removal of heavy metals (HMs) during electrokinetic remediation (EKR). Acid pretreatment offers the possibility to solve this problem. In this study, four pretreatment solutions (deionized water, $\mathrm{HNO}_{3}, \mathrm{HCl}$ and $\mathrm{HAc}$ ) were investigated with the aim of lowering the high acid buffering capacity of MSWI fly ash. A series of laboratory scale EKR experiments were conducted with different pretreatment conditions and operating parameters. The experiment with $\mathrm{HCl}$ pretreatment showed the best removal of HMs. Then, an orthogonal experiment was designed to explore the optimum EKR conditions based on acid pretreatment. The results showed that the best leaching efficiencies of $\mathrm{Pb}(94.23 \%), \mathrm{Zn}(89.09 \%), \mathrm{Cu}(88.21 \%)$ and $\mathrm{Cd}(84.97 \%)$ were obtained after $15 \mathrm{~d}$, at a voltage gradient of $2 \mathrm{~V} / \mathrm{cm}$ and with the addition of $0.05 \mathrm{~mol} / \mathrm{L}$ citric acid to the catholyte every day. The carbonate and alkaline oxides in fly ash were significantly reduced after the EKR treatment, as confirmed by XRD analysis. Sequential extraction of $\mathrm{Pb}, \mathrm{Zn}, \mathrm{Cu}$ and $\mathrm{Cd}$ indicated that the oxidizable and reducible states were converted to a more stable compound after treatment.

Keywords: Electrokinetic remediation; Acid pretreatment; MSWI fly ashes; Heavy metals; Removal efficiency; Buffering capacity 


\section{FULL TEXT}

(C) 2020 The Authors. Published by ESG (www.electrochemsci.org). This article is an open access article distributed under the terms and conditions of the Creative Commons Attribution license (http://creativecommons.org/licenses/by/4.0/). 